\title{
Kinetics of Hydrogen Absorption and Desorption in $\mathrm{LaNi}_{5-x} \mathrm{Al}_{x}$ Slurries
}

\author{
E. D. Snijder, G. F. Versteeg, and W. P. M. van Swaaij \\ Dept. of Chemical Engineering, Twente University of Technology, 7500 AE Enschede, The Netherlands
}

The kinetics of hydrogen absorption and desorption in $\mathrm{LaNi}_{4.8} A l_{0.2}, \mathrm{LaNi}_{4.9} A \mathrm{I}_{0.1}$ and $\mathrm{LaNi}_{5}$, suspended in cyclohexane and $\mathrm{LaNi}_{5}$ in ethanol have been investigated. The absorption process can be described in terms of mass transfer and reaction resistances in series. The rate-limiting steps for this process are dissolution of hydrogen in the solvent and the reaction of hydrogen with the metal alloy. Over a broad range of hydrogen loadings, the reaction of hydrogen with the metal follows the rate equation:

$$
R_{\mathrm{abs}}=k_{a} a_{s}\left(C_{\mathrm{H}_{2}, s}-C_{\mathrm{eq}, a}\right)
$$

This type of kinetic equation indicates that during hydride formation in a slurry a surface process is the rate-determining step, which was confirmed by the observed influence of the solvent. Desorption of hydrogen can be described best with a shrinking core relation:

$$
1-(1-X)^{1 / 3}=k_{d} \ln \left(\frac{P_{\mathrm{eq}, d}}{P_{\mathrm{H}_{2}}}\right) t
$$

The phase transformation at the $\beta / \alpha$ boundary appears to be the rate-determining step. Alloys with higher aluminum contents produce a lower reaction rate constant.

\section{Introduction}

The determination of hydrogen absorption and desorption rates by hydride forming metal alloys (for example, $\mathrm{LaNi}_{5}$, $\mathrm{FeTi}, \mathrm{Mg}_{2} \mathrm{Ni}$ ) has received much attention in the literature. These alloys can be applied in gas-solid systems (Goodell and Rudman, 1983) and they can be suspended in inert solvents (Beenackers and van Swaaij, 1982; Johnson and Reilly, 1986). Knowledge of the absorption/desorption rates is necessary for a good dimensioning of hydrogen recovery units (Holstvoogd et al., 1989). A relatively new application of metal hydrides is their use as catalysts (Wallace et al., 1980). The hydrogen transport from the bulk of the metal hydride particles to the surface is an important step during a hydrogenation reaction with hydrogen which is supplied by the hydride. Therefore, the hydrogen desorption kinetics are required for a complete understanding of the hydrogenation mechanism. The experiments as described in the present study, are a part of the investigations on cyclohexene hydrogenation with $\mathrm{LaNi}_{4.8} \mathrm{Al}_{0.2}$, $\mathrm{LaNi}_{4.9} \mathrm{Al}_{0.1}$ and $\mathrm{LaNi}_{5}$, suspended in cyclohexane or ethanol (Snijder et al., 1992). The absorption rates of hydrogen in these slurries have been measured in the present work.

\section{Theory}

The ability of alkali and earth alkali to react with hydrogen in order to form metal hydrides has been discovered already almost a century ago. Well-known examples are $\mathrm{LiH}$ and $\mathrm{NaH}$ in which the interaction between the metal and hydrogen is via an ionic bond. Later, hydrides like $\mathrm{LiAlH}_{4}, \mathrm{NaBH}_{4}$ and types with a covalent bond based on $\mathrm{BH}_{3}$ have been developed. A new class of hydride forming metal alloys was developed in the late 1960s. Examples are $\mathrm{FeTi}, \mathrm{Mg}_{2} \mathrm{Ni}$ (Reilly and Wiswall, 1968, 1974) and $\mathrm{LaNi}_{5}$ (Van Vucht et al., 1970). These are 


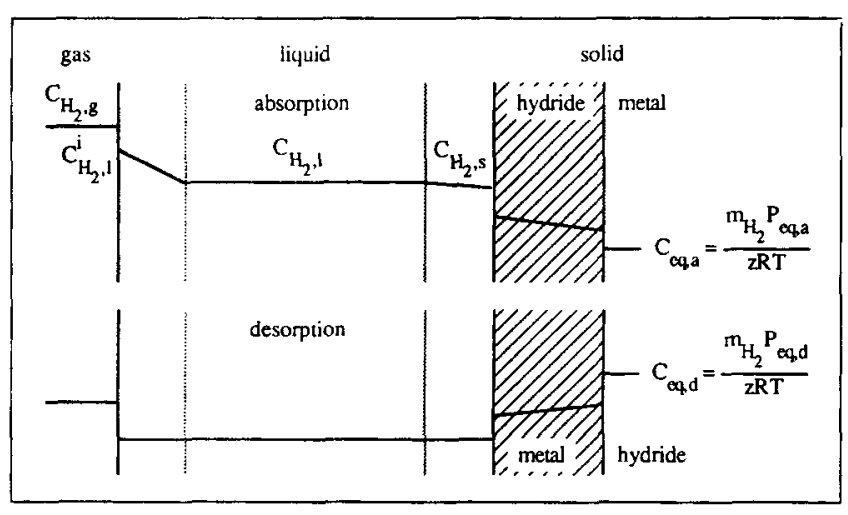

Figure 1. Film model representation of hydrogen absorption and desorption in a slurry.

crystalline metal alloys which absorb hydrogen in free interstitial sites of the crystal structure, the type of bonding is of a metallic nature (Reilly, 1977).

Several mass transfer and reaction steps take place when hydrogen is absorbed in a metal hydride, see for example, Flanagan (1978) and Park and Lee (1982). On the surface of the particles, two different regions have been recognized: Ni and $\mathrm{La}_{2} \mathrm{O}_{3} / \mathrm{La}(\mathrm{OH})_{3}$ (Wallace et al., 1979). During absorption, hydrogen is chemisorbed and dissociated on the nickel. $\mathrm{H}$ atoms diffuse on the nickel surface to the $\mathrm{Ni}-\mathrm{La}_{2} \mathrm{O}_{3}$ interface, along the boundary between the $\mathrm{Ni}$ and $\mathrm{La}_{2} \mathrm{O}_{3}$ regions to the underlying metal hydride and then through the hydride $(\beta$ phase) to the unconverted metal ( $\alpha$ phase). Here the phase transformation takes place. For desorption these processes proceed vice versa.

When a metal hydride is suspended in an inert solvent, two additional mass-transfer steps have to be included, as was done earlier by Ptasinski et al. (1986) and Tung et al. (1986). The following steps can be distinguished:

$$
J_{\mathrm{H}_{2}} a_{s}=k_{s} a_{s}\left(C_{\mathrm{H}_{2},}-C_{\mathrm{H}_{2}, s}\right)
$$

If the bulk concentration $\left(C_{\mathrm{H}_{2},}\right)$ is constant, both fluxes are equal to the hydrogen absorption rate: $J_{\mathrm{H}_{2}} a=J_{\mathrm{H}_{2}} a_{s}=R_{\mathrm{abs}}$. Furthermore, it is assumed that at the gas-liquid interface both phases are in equilibrium. Applying Henry's law gives $C_{\mathrm{H}_{2}, d}^{i}$ (with $C_{\mathrm{H}_{2}, l}^{i}=m_{\mathrm{H}_{2}} C_{\mathrm{H}_{2}, 8}$ ). Equations 1 and 2 can be rearranged to:

$$
C_{\mathrm{H}_{2}, s}=m_{\mathrm{H}_{2}} C_{\mathrm{H}_{2}, 8}-R_{\mathrm{abs}}\left(\frac{1}{k_{1} a}+\frac{1}{k_{5} a_{s}}\right)
$$

The absorption rate $R_{\text {abs }}$ is determined experimentally. With data for $k a$ and $k_{s} a_{s}$, the concentration close to the surface $C_{\mathrm{H}_{2},}$ can be calculated according to Eq. 3. The rate limiting step for hydrogen absorption in a metal hydride, suspended in a solvent, can then be obtained from the relation between $R_{\text {abs }}, C_{\mathrm{H}_{2}, s}$ and the hydrogen concentration in the hydride.

For the analysis of the desorption experiments, the method of Hancock and Sharp (1972) was applied. They proposed to use a generalized equation, based on the Johnson-Mehl-Avrami (JMA) relation (Avrami, 1939, 1940, 1941; Johnson and Mehl, 1939), for the description of the solid phase reaction.

$$
X=1-\exp \left(-B t^{q}\right)
$$

The fraction reacted $X$ is related to the hydrogen storage capacity of the hydride $F$ according to:

$$
\begin{aligned}
X=1 & -\frac{F}{F_{0}} \\
& \text { with } F=\frac{\text { number of hydrogen atoms }}{\text { La atoms }}=\frac{2 n_{\mathrm{H}_{2} \text {,hdr }}}{m_{\mathrm{hydr}} / M_{\mathrm{hydr}}}
\end{aligned}
$$
(1) $\mathrm{H}_{2}(\mathrm{~g}) \Leftrightarrow \mathrm{H}_{2}(l)$
(2) $\mathrm{H}_{2}(l) \Leftrightarrow \mathrm{H}_{2}(s)$
(3) $\mathrm{H}_{2}$ (s) $\Leftrightarrow \mathrm{H}_{2}$ (ads)
(4) $\mathrm{H}_{2}$ (ads) $\Leftrightarrow 2 \mathrm{H}$ (ads)
(5) $\mathrm{H}($ ads $) \Leftrightarrow H(\alpha-\beta$ interface $)$
(6) $\mathrm{H}(\alpha) \Leftrightarrow \mathrm{H}(\beta)$
mass transfer from gas to liquid
mass transfer from liquid to solids
chemisorption of hydrogen on the metal surface
dissociation of hydrogen into atoms
diffusion on the Ni surface and in the bulk of the material
phase transformation at the metal/metal hydride interface

The various steps for both absorption and desorption are shown in Figure 1. Since all steps occur simultaneously, the slowest step will limit the rate of the total process.

For pure hydrogen, no gas phase mass-transfer resistance will occur and the first mass-transfer step for hydrogen entering the slurry is at the liquid side of the gas-liquid interface. The volumetric mass-transfer coefficient $k a$ characterizes this step. Around the metal particles there is another diffusion layer, the corresponding volumetric mass-transfer coefficient is the $k_{5} a_{s}$. When it is assumed that the mass-transfer processes are in series (for further discussion on that subject, see the discussion section), the molar fluxes through the interfaces can be written as:

$$
J_{\mathrm{H}_{2}} a=k, a\left(C_{\mathrm{H}_{2}, l}^{i}-C_{\mathrm{H}_{2}, l}\right)
$$

Plotting $\ln (-\ln (1-X))$ vs. $\ln (t)$ yields $q$ as the slope of the line. For $0.15 \leq X \leq 0.5$ the value of $q$ roughly indicates which rate equation may describe the reaction best. Some values for $q$ and the corresponding rate equations are presented in Table 1 (Hancock and Sharp, 1972). Three groups of relations can be recognized: diffusion controlled $\left(D_{1}, D_{3}\right)$, reaction controlled (zero-order, first-order, $R_{3}$ ) and processes which follow the JMA equation $\left(A_{2}, A_{3}\right)$. Subsequently, the precise mechanism can be obtained by plotting some selected rate equations (based on the value of $q$ ) over a wider range for $X$. According to Reilly et al. (1989), hydrogen bubbles are formed on the metal surface during hydrogen desorption from a hydride slurry. The metal hydride is then in equilibrium with the gas phase and concentration gradients in the liquid phase are absent during desorption, as shown in Figure 1. 
Table 1. Different Rate Limiting Mechanisms for Solid Phase Reactions According to Hancock and Sharp (1972)

\begin{tabular}{cll}
\hline$q$ & \multicolumn{1}{c}{ Model } & \multicolumn{1}{c}{ Equation } \\
\hline 0.62 & $D_{1}$ & $X^{2}=k t$ \\
0.54 & $D_{3}$ & {$\left[1-(1-X)^{1 / 3}\right]^{2}=k t$} \\
1.00 & first-order & $-\ln (1-X)=k t$ \\
1.07 & $R_{3}$ & $1-(1-X)^{1 / 3}=k t$ \\
1.24 & zero-order & $X=k t$ \\
2.00 & $A_{2}$ & {$[-\ln (1-X)]^{1 / 2}=k t$} \\
3.00 & $A_{3}$ & {$[-\ln (1-X)]^{1 / 3}=k t$} \\
\hline
\end{tabular}

\section{Experimental Procedure \\ Experimental setups and activation}

The experiments were carried out in two parallel setups (I and II), the experimental technique is identical for both. A schematic flowsheet is given in Figure 2. The addition of hydrogen from a storage vessel $V_{a}$ to the stirred batch reactor takes place through a pressure regulator, resulting in a constant hydrogen pressure in the reactor throughout an experiment. Hydrogen consumption in the slurry is determined by means of the pressure drop in the storage vessel. Via a back pressure regulator the reactor is connected to another vessel, $V_{d}$. During a desorption experiment the reactor is kept at a constant pressure by venting the evolved hydrogen through the back pressure regulator. Hydrogen desorption is followed by measuring the pressure increase in the previously evacuated desorption vessel. The experimental conditions and the geometrical details of both setups are listed in Table 2. Prior to the use in the experiments, the solvents are stored on molecular sieves for a few days and then degassed with oxygen free nitrogen (treated with active $\mathrm{Cu}_{2} \mathrm{O}$ catalyst) and finally stored under nitrogen.

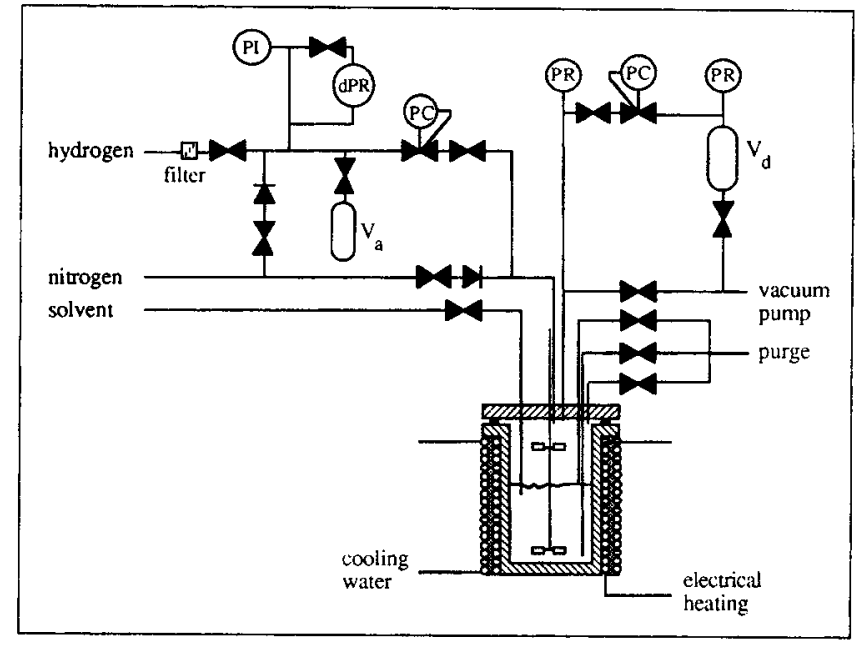

Figure 2. Experimental setup.

The metal alloys $\mathrm{LaNi}_{4.8} \mathrm{Al}_{0.2}$ and $\mathrm{LaNi}_{5}$ were provided by Japan Metals \& Chemicals (JMC), $\mathrm{LaNi}_{4.9} \mathrm{Al}_{0.1}$ was obtained from Highways International. Cyclohexane and ethanol were supplied by Merck $(\geq 99.9 \%)$ and hydrogen by Hoekloos ( $\geq 99.999 \%$ ). At $333 \mathrm{~K}$ the raw materials were first activated by about 20 hydriding/dehydriding cycles with hydrogen (at 25 bar and at 0.1 mbar resp.). After addition of solvent to the reactor still more cycles were carried out, in total about 4050. During the activation process, the particles pulverize until a stable diameter is reached. Several properties of the slurries are given in Table 3 . The density of the alloys $\left(\rho_{\text {hydr }}\right)$ was determined with a pycnometer, using methanol as solvent. Equilibrium measurements for the hydrogen/metal hydride

Table 2. Experimental Conditions

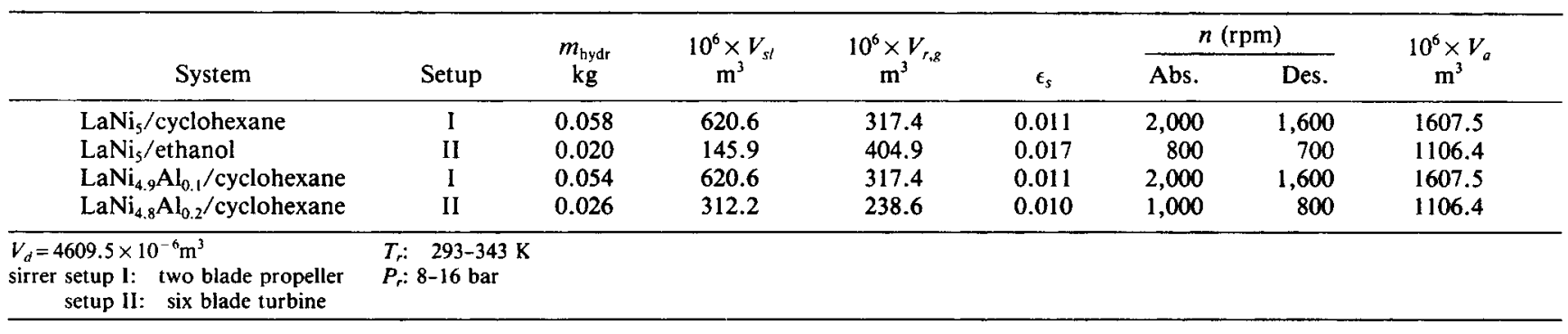

Table 3. Properties of the Shurries

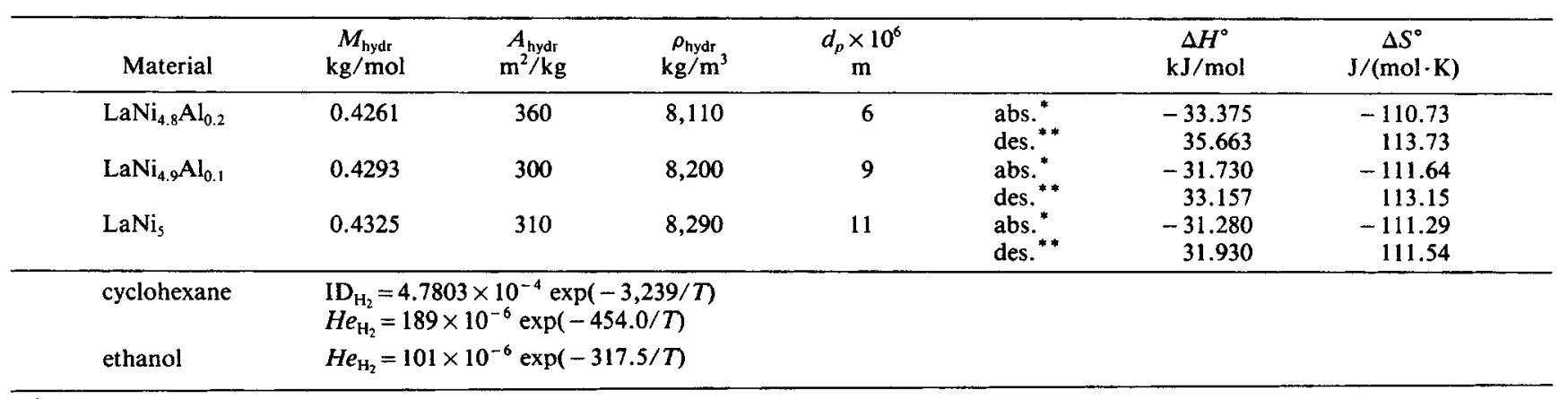

\footnotetext{
*Absorption
}

** Desorption 
system have been carried out in a separate setup, consisting of a reactor and a hydrogen storage vessel. After the supply of a small amount of hydrogen to the reactor, equilibrium was allowed to establish. The temperature and pressure both in the reactor and storage vessel were recorded, next, a new amount of hydrogen was supplied to the reactor. This was repeated until the maximum pressure was reached. With the obtained data the amount of hydrogen in the hydride $F$ has been derived. The $\Delta H^{\circ}$ and $\Delta S^{\circ}$ values as listed in Table 3 were calculated with the experimentally determined relations for the equilibrium pressures as a function of $1 / T$ by the application of a van't Hoff relation $\left(\ln \left(P_{e q}=\Delta H^{\circ} / R T-\Delta S^{\circ} / T\right)\right.$. More details are provided by Snijder (1992). With the completely pulverized metal powder, the determination of the surface area $\left(A_{\text {hydr }}\right)$ and the particle-size distribution were performed. The surface area has been measured by means of nitrogen adsorption at $77 \mathrm{~K}$. The particle-size distribution, resulting in an average particle diameter, has been obtained with a laser diffraction particle-size distribution analyzer (Horiba LA-500). The solubility of hydrogen in cyclohexane is presented as a Henry coefficient and was measured in a separate gas/liquid equilibrium setup. The hydrogen solubility is related to the Henry coefficient according to: $m_{\mathrm{H}_{2}}=H e_{\mathrm{H}_{2}} R T$. The values for ethanol are available in the literature (Clever, 1981). Finally, the diffusion coefficient of hydrogen in cyclohexane was determined in the diaphragm cell as described by Littel et al. (1992).

\section{Absorption}

Before every absorption experiment the metal hydride is desorbed until the reactor pressure is equal to the vapor pressure of the solvent. The reactor is then pressurized up to the desired value, after which the stirrer is started. During the hydrogen absorption the pressure in the storage vessel and the temperature in the reactor are recorded. The reactor pressure is kept constant within 0.02 bar, the temperature increase depends on the pressure and temperature in the reactor (typically $2-4 \mathrm{~K}$ ). The hydrogen absorption rate $R_{\mathrm{abs}}$ can be calculated with the pressure change in the absorption storage vessel $V_{a}$ :

$$
R_{\mathrm{abs}}=-\frac{V_{a}}{z_{a} R T_{a} V_{\mathrm{sl}}} \frac{d P_{a}}{d t}
$$

According to Ptasinski et al. (1986) and Tung et al. (1986) the value of the $k a$ is not influenced appreciably by small metal particles at low volume concentrations. In the present investigations the slurries contain only $1-2 \mathrm{vol} \%$ metal alloy. Therefore, the value of $k a$ can be determined by measuring the absorption rate in pure solvents at experimental conditions which are identical to those during hydrogen absorption in the slurry. Before hydrogen absorption, the solvent is completely desorbed. After the supply of hydrogen to the reactor, the stirrer is started. During the absorption experiment no further hydrogen is supplied to the reactor and the pressure in the reactor follows the equation:

$\frac{V_{g}}{z_{r} R T_{r}} \frac{d P_{\mathrm{H}_{2}}}{d t}=-k_{r} a\left(\frac{m_{\mathrm{H}_{2}} P_{\mathrm{H}_{2}}}{z_{r} R T_{r}}-C_{\mathrm{H}_{2}, t}\right) V_{l}$

$$
\text { at } t=0: \quad P_{\mathrm{H}_{2}}=P_{0}, \quad C_{\mathrm{H}_{2}, t}=0
$$

An overall mass balance provides the hydrogen concentration in the liquid bulk, $P_{f}$ is the final pressure:

$$
C_{\mathrm{H}_{2},} V_{l}+\frac{P_{\mathrm{H}_{2}}}{z_{r} R T_{r}} V_{g}=\frac{P_{f}}{z_{r} R T_{r}}\left(m_{\mathrm{H}_{2}} V_{l}+V_{g}\right)
$$

Substitution of $C_{\mathrm{H}_{2}, l}$, as derived from relation 8 , into Eq. 7 , followed by the integration of the differential equation yields:

$$
\ln \left(\frac{P_{\mathrm{H}_{2}}-P_{f}}{P_{0}-P_{f}}\right)=-\left(\frac{m_{\mathrm{H}_{2}} V_{l}}{V_{g}}+1\right) k_{a} a t
$$

Constructing a Figure with the lefthand term of Eq. 9 against time yields $k_{1} a\left(1+m_{\mathrm{H}_{2}} V_{l} / V_{g}\right)$ as slope of the curve.

The determination of the mass-transfer coefficient $k_{s}$ has been studied extensively, for example, Sano et al. (1974), Marrone and Kirwan (1986) and Armenante (1983). Generally, the results are presented in dimensionless form as a Sherwood relation:

$$
S h=2+\operatorname{const}\left(\frac{E_{p} d_{p}^{4}}{\nu^{3}}\right)^{n} S c^{1 / 3}
$$

The power input $E_{p}$ has to be estimated with relations as given by for example, Bates et al. (1963). In the case of very small particles $\left(10^{-5} \mathrm{~m}\right)$ and a kinematic viscosity of about $10^{-6}$ $\mathrm{m}^{2} / \mathrm{s}$ for cyclohexane the second part of the righthand term will be small, even for a relatively large power input. In the present study $S h=2$ was taken as a conservative estimate. Finally, the outer surface of the particles $a_{s}$ has been calculated with:

$$
a_{s}=A_{\text {hydr }} \rho_{\text {hydr }} \epsilon_{s}
$$

It appeared that the calculated $k_{s} a_{s}$ using the conservative estimate for the $S h$ number, was for all conditions very large as compared to the $k, a$. Therefore, a better estimate for the Sherwood number will not have any effect on the results.

\section{Desorption}

The desorption experiments have been carried out according to the procedure as presented by Reilly et al. (1989). First the hydride slurry was saturated at 0.5 to 1 bar above the absorption equilibrium pressure. The hydrogen pressure was reduced through the back pressure valve till $0.5-2.5$ bar below the desorption equilibrium pressure, after which the stirrer was started immediately. The pressure in the desorption vessel and the reactor temperature were recorded, the reactor pressure was kept constant within 0.03 bar.

The number of moles of hydrogen in the hydride (which provides $F$ ) was obtained from an overall hydrogen balance over the reactor and desorption vessel $\left(n_{\mathrm{H}_{2}, d, 0}=0\right.$, since $P_{d, 0}$ $=0$ ):

$$
n_{\mathrm{H}_{2}, \mathrm{hydr}}=n_{\mathrm{H}_{2}, \mathrm{hydr}, 0}-n_{\mathrm{H}_{2}, d}+\left(n_{\mathrm{H}_{2}, t, 0}-n_{\mathrm{H}_{2}, l}\right)
$$

The slurry is initially saturated at a pressure which is 4 to 5 bar higher than during the desorption experiment. Therefore, 
the liquid will desorb the excess absorbed hydrogen until a new gas/liquid equilibrium is reached. As elucidated in the theory section, the metal hydride particles are in equilibrium with the gas phase. This also implies that the liquid has to be in equilibrium with the gas phase. Consequently, hydrogen desorption from the liquid follows the mass balance:

$V_{l} \frac{d C_{\mathrm{H}_{2}, l}}{d t}=-k_{l, d} a\left(C_{\mathrm{H}_{2},}-C_{\mathrm{H}_{2}, l}^{i}\right)$

$$
\text { with at } t=0: C_{\mathrm{H}_{2}, l}=m_{\mathrm{H}_{2}} P_{0} /\left(z_{r} R T_{r}\right)
$$

Substitutions according to Henry's law and integration between the pressures $P_{0}$ and $P_{\mathrm{H}_{2}}$ yields:

$$
n_{\mathrm{H}_{2}, l, 0}-n_{\mathrm{H}_{2}, l}=\frac{m_{\mathrm{H}_{2}} V_{l}}{z_{r} R T_{r}}\left(P_{0}-P_{\mathrm{H}_{2}}\right)\left[1-\exp \left(-k_{l, d} a t\right)\right]
$$

The mass-transfer coefficient during desorption $\left(k_{l, d} a\right)$ is again experimentally determined with the pure solvents. During desorption from a slurry, additional hydrogen bubbles are formed on the surface of the hydride particles, resulting in an increase of the G/L interfacial area $a$. The value of $k_{l, d} a$ which is measured with pure solvents, is only a conservative estimate then. Almost the same procedure as during desorption from the slurry has been applied, however, no hydrogen is vented through the back pressure regulator. In this case the pressure increase in the reactor is recorded, it follows the equation:

$$
\frac{V_{g}}{z_{r} R T} \frac{d P_{\mathrm{H}_{2}}}{d t}=k_{l, d} a\left(C_{\mathrm{H}_{2}, t}-\frac{m_{\mathrm{H}_{2}} P_{\mathrm{H}_{2}}}{z_{r} R T_{r}}\right) \text { at } t=0: \quad P_{\mathrm{H}_{2}}=P_{0}
$$

The overall mass balance (Eq. 8) yields $C_{\mathrm{H}_{2},}$, substitution in Eq. 15 and integration of the differential equation gives:

$$
\ln \left(\frac{P_{f}-P_{\mathrm{H}_{2}}}{P_{f}-P_{0}}\right)=-\left(\frac{m_{\mathrm{H}_{2}} V_{l}}{V_{g}}+1\right) k_{l, d} \text { at }
$$

Plotting the lefthand term against time provides $k_{l, d} a(1$ $\left.+m_{\mathrm{H}_{2}} V_{l} / V_{g}\right)$ as the slope of the line.

\section{Results}

\section{Absorption experiments}

In order to determine the gas/liquid mass-transfer coefficient $k a$, absorption experiments with pure solvents have been carried out. This has been performed in both setups, the results are given as Arrhenius expressions:

$\begin{array}{lll}\text { cyclohexane } & \left(\mathrm{LaNi}_{5}, \mathrm{LaNi}_{4.9} \mathrm{Al}_{0.1}\right) & \text { setup I, 2,000 rpm } \\ \text { cyclohexane } & \left(\mathrm{LaNi}_{4.8} \mathrm{Al}_{0.2}\right) & \text { setup I, 1,000 rpm } \\ \text { ethanol } & \left(\mathrm{LaNi}_{5}\right) & \text { setup II, 800 rpm }\end{array}$

cyclohexane ( $\left.\mathrm{LaNi}_{5}, \mathrm{LaNi}_{4.9} \mathrm{Al}_{0.1}\right)$ setup 1, 2,000 rpm ethanol $\left(\mathrm{LaNi}_{5}\right)$

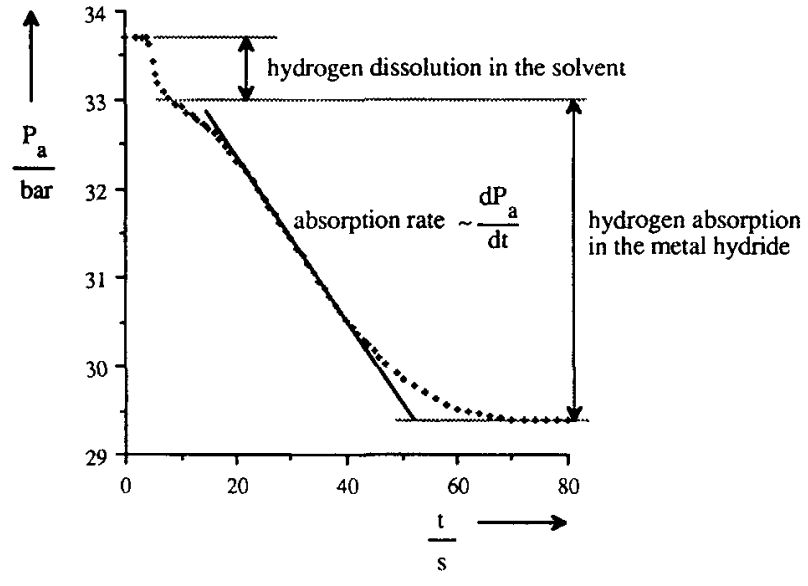

Figure 3. Pressure in the absorption vessel as a function of time during hydrogen absorption in a $\mathrm{LaNi}_{5}$ / cyclohexane slurry at $323 \mathrm{~K}$ and 12 bar.

hydrogen absorption in a slurry. According to Eq. 6, the absorption rate is related to the slope of the curve. First the liquid is saturated (very fast process), next, the absorption rate in the metal initially increases until a constant value is reached and it decreases again at the end of the experiment. This result can be explained using the nucleation and growth model, which will be discussed in the discussion section. The constant value was taken as $R_{\text {abs }}$ as it constitutes the largest part of the absorption process. For the $\mathrm{LaNi}_{4.8} \mathrm{Al}_{0.2}$ and $\mathrm{LaNi}_{5}$ in cyclohexane slurries the hydrogen pressure was varied to evaluate its effect on $R_{\text {abs. }}$. The hydrogen concentration close to the hydride surface $C_{\mathrm{H}_{2}, s}$ was calculated with Eq. 3 and Figure 4 shows the results. The absorption rate depends linearly on $C_{\mathrm{H}_{2}, s}$, the slope is equal to a rate constant and the intercept with the horizontal axis appears to be equal to the equilibrium concentration $C_{\mathrm{eq}, a}$ :

$$
R_{\mathrm{abs}}=k_{a} a_{s}\left(C_{\mathrm{H}_{2}, s}-C_{\mathrm{eq}, a}\right) \quad \text { with } C_{\mathrm{eq}, a}=\frac{m_{\mathrm{H}_{2}} P_{\mathrm{cq}, a}}{z_{r} R T_{r}}
$$

Based on these results, it was assumed that this rate equation also holds for hydrogen absorption in $\mathrm{LaNi}_{5}$ /ethanol and $\mathrm{LaNi}_{4.9} \mathrm{Al}_{0.1}$ /cyclohexane. Since the mass-transfer steps and the reaction step (Eqs. 1, 2 and 17) are all first-order in hydrogen, $C_{\mathrm{H}_{2}, 1}$ and $C_{\mathrm{H}_{2}, s}$ can be eliminated:

$$
R_{\mathrm{abs}}=k_{\mathrm{ov}} \frac{m_{\mathrm{H}_{2}}}{z_{r} R T_{r}}\left(P_{\mathrm{H}_{z}}-P_{\mathrm{eq}, a}\right)
$$

The influence of pressure on the $k a$ was found to be small for a pressure range of 4-16 bar, the relations as presented above have been determined at pressures between 10 and 12 bar.

Figure 3 represents a typical result of the experimentally determined variation of the pressure in the storage vessel during $k_{,} a=32.14 \exp \left(-10.74 \times 10^{3} / \mathrm{RT}\right)$
$k a=34.17 \exp \left(-10.28 \times 10^{3} / \mathrm{RT}\right)$
$k_{1} a=227.88 \exp \left(-14.46 \times 10^{3} / \mathrm{RT}\right)$

The overall transfer resistance $1 / k_{o v}$ consists of a series of three 


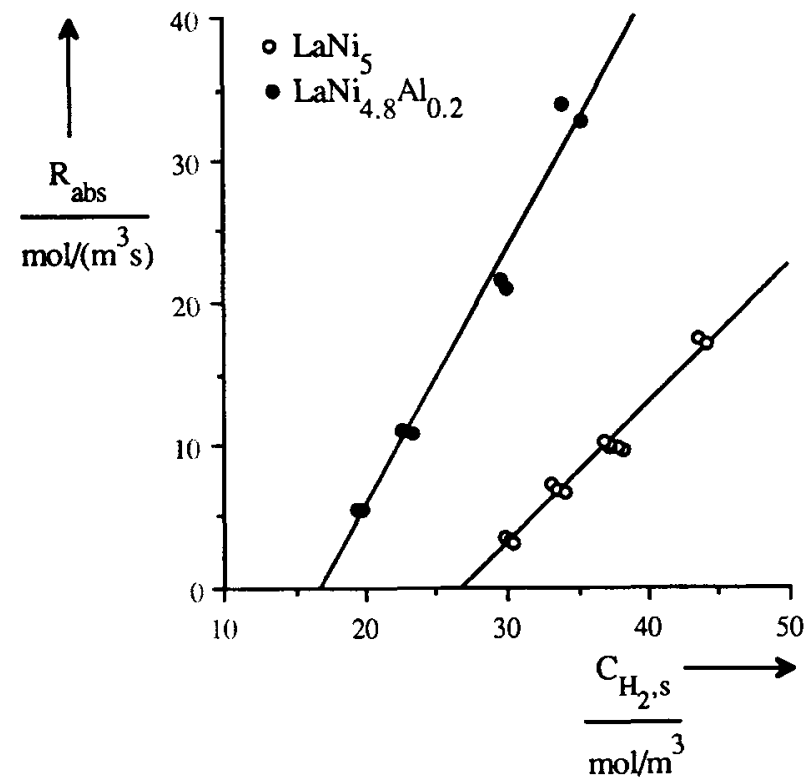

Figure 4. Absorption rate against the hydrogen concentration close to the solid surface $\left(\mathrm{C}_{\mathrm{H}_{2}, \mathrm{~s}}\right)$ for $\mathrm{LaNi}_{4.8} \mathrm{Al}_{0.2}(333 \mathrm{~K})$ and $\mathrm{LaNi}_{5}(323 \mathrm{~K})$ in cyclohexane.

transfer resistances. The value of $k_{\text {ov }}$ can be calculated according to Eq. 18 using the measured $R_{\text {abs }}$ and $P_{\mathrm{H}_{2}}$. Subsequently, Eq. 19 yields the kinetic rate constant for the absorption in the hydride, provided that the $k a$ and $k_{s} a_{s}$ are available.

Figures $5 \mathrm{a}$ and $5 \mathrm{~b}$ illustrate the influence of the temperature on the reaction rate constants $k_{a} a_{s}$ divided by the volume fraction $\epsilon_{s}$. The following relations were derived:

$\mathrm{LaNi}_{\varsigma}$ cyclohexane $\frac{k_{a} a_{s}}{\epsilon_{s}}=2.59 \times 10^{6} \exp \left(\frac{-27.6 \times 10^{3}}{\mathrm{RT}}\right)$

$\mathrm{LaNi}_{5}$ ethanol $\frac{k_{a} a_{s}}{\epsilon_{s}}=4.48 \times 10^{6} \exp \left(\frac{-27.5 \times 10^{3}}{\mathrm{RT}}\right)$

$\mathrm{LaNi}_{4.9} \mathrm{Al}_{0.1}$ cyclohexane $\frac{k_{a} a_{s}}{\epsilon_{s}}=3.84 \times 10^{6} \exp \left(\frac{-27.7 \times 10^{3}}{\mathrm{RT}}\right)$

$\mathrm{LaNi}_{4.8} \mathrm{Al}_{0.2}$ cyclohexane $\frac{k_{a} a_{s}}{\epsilon_{s}}=1.82 \times 10^{6} \exp \left(\frac{-25.4 \times 10^{3}}{\mathrm{RT}}\right)$

\section{Desorption experiments}

As with the absorption experiments, measurements with pure solvents have been carried out in order to determine the $k_{l, a} a$, giving the following relations:

cyclohexane ( $\left.\mathrm{LaNi}_{5}, \mathrm{LaNi}_{4.9} \mathrm{Al}_{0.1}\right)$ setup I, 1,600 rpm cyclohexane $\left(\mathrm{LaNi}_{4.8} \mathrm{Al}_{0.2}\right)$ setup II, $800 \mathrm{rpm}$

For the $k_{l, d} a$ of ethanol in setup II at $700 \mathrm{rpm}$ the measured $k a$ for absorption at $\mathbf{8 0 0} \mathrm{rpm}$ was taken as an estimate.
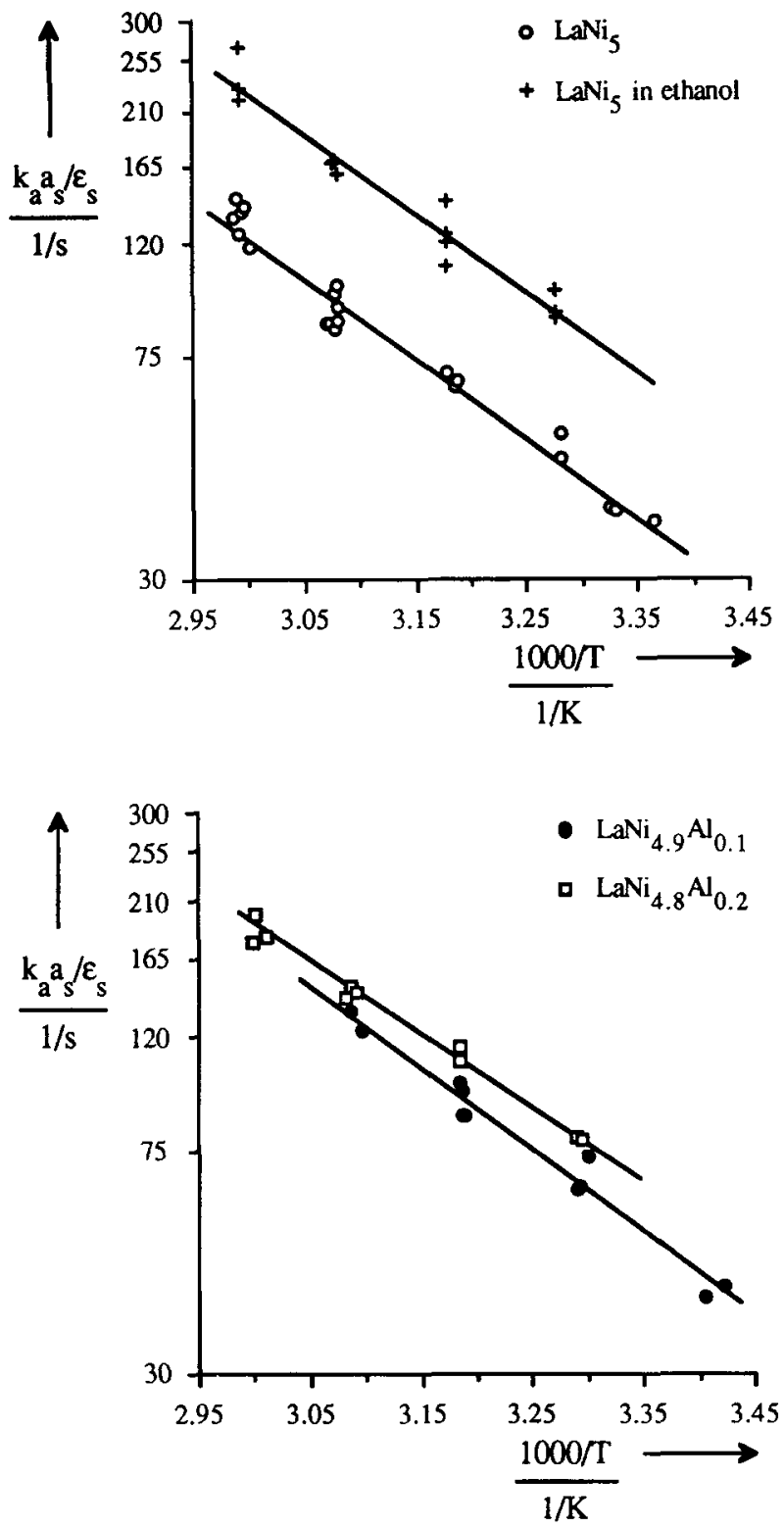

Figure 5a,b. Arrhenius plot for the absorption rate constants.

During hydrogen desorption from the slurry the pressure in the desorption vessel was recorded, Figure 6 gives an example of the obtained result. After a sharp increase at the start, due to desorption from the solvent, the desorption rate gradually decreases until the hydride is empty. With Eq. 12 the hydrogen capacity $F$ has been calculated. Next, a first indication of the rate controlling mechanism was obtained by constructing a curve according to Eq. 4. However, a relatively large spread in the slope $q$ was found $(0.9-1.9)$, so it was not yet possible

$k_{l, d} a=225.4 \exp \left(-14.5 \times 10^{3} / \mathrm{RT}\right)$

$k_{l, a} a=6,180.2 \exp \left(-23.8 \times 10^{3} / \mathrm{RT}\right)$

to distinguish between the different models for reaction controlled rates and phase boundary controlled rate. The zero- 


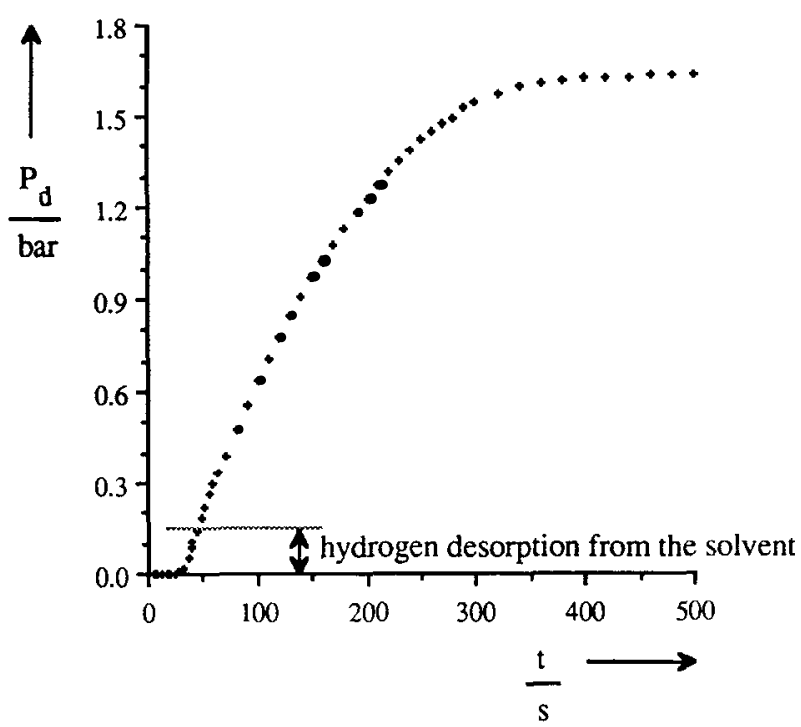

Figure 6. Pressure in the desorption vessel as a function of time during hydrogen desorption from a $\mathrm{LaNi}_{5} /$ cyclohexane slurry at $323 \mathrm{~K}$ and $3.5 \mathrm{bar}$.

order model, the first-order model and the shrinking core model have been examined in more detail by drawing the corresponding relations over a wider range for $X$. The shrinking core model fitted the experimental results best for almost the complete desorption time and for all slurries:

$$
1-(1-X)^{1 / 3}=k_{d}^{\prime} t
$$

At the highest temperature $(343 \mathrm{~K})$, the experimental results for $\mathrm{LaNi}_{5}$ could be fitted with $\mathrm{Eq} .20$ for only a narrow range of the hydrogen storage capacity $F$. This has also been reported by Reilly et al. (1989) and can probably be attributed to the fact that at higher temperatures, the equilibrium between the $\alpha$ and $\beta$ phase exists in a narrow region for $F$.

It appeared that the observed rate constant $k_{d}^{\prime}$ increases when the difference between the equilibrium desorption pressure and the reactor pressure becomes larger. According to Flanagan (1978) and Reilly et al. (1989) the driving force for this phase boundary controlled process is $\ln \left(P_{\mathrm{eq}, d} / P_{\mathrm{H}_{2}}\right)$. The rate constant $k_{d}^{\prime}$ has been divided by $\ln \left(P_{\text {eq, } d} / P_{\mathrm{H}_{2}}\right)$ in order to obtain the $k_{d}$. Consequently, the equation which describes the desorption process reads:

$$
1-(1-X)^{1 / 3}=k_{d} \ln \left(\frac{P_{\mathrm{eq}, d}}{P_{\mathrm{H}_{2}}}\right) t
$$

Figures $7 \mathrm{a}$ and $7 \mathrm{~b}$ show the desorption rate constants $k_{d}$ as a function of temperature. The crosses denote the values for $\mathrm{LaNi}_{s}$ suspended in ethanol, which appear to be practically identical to the values as measured in cyclohexane. For the hydrides suspended in cyclohexane, the following relations have been derived:

$$
\mathrm{LaNi}_{5} \quad k_{d}=13.5 \times 10^{3} \exp \left(\frac{-39.8 \times 10^{3}}{\mathrm{RT}}\right)
$$
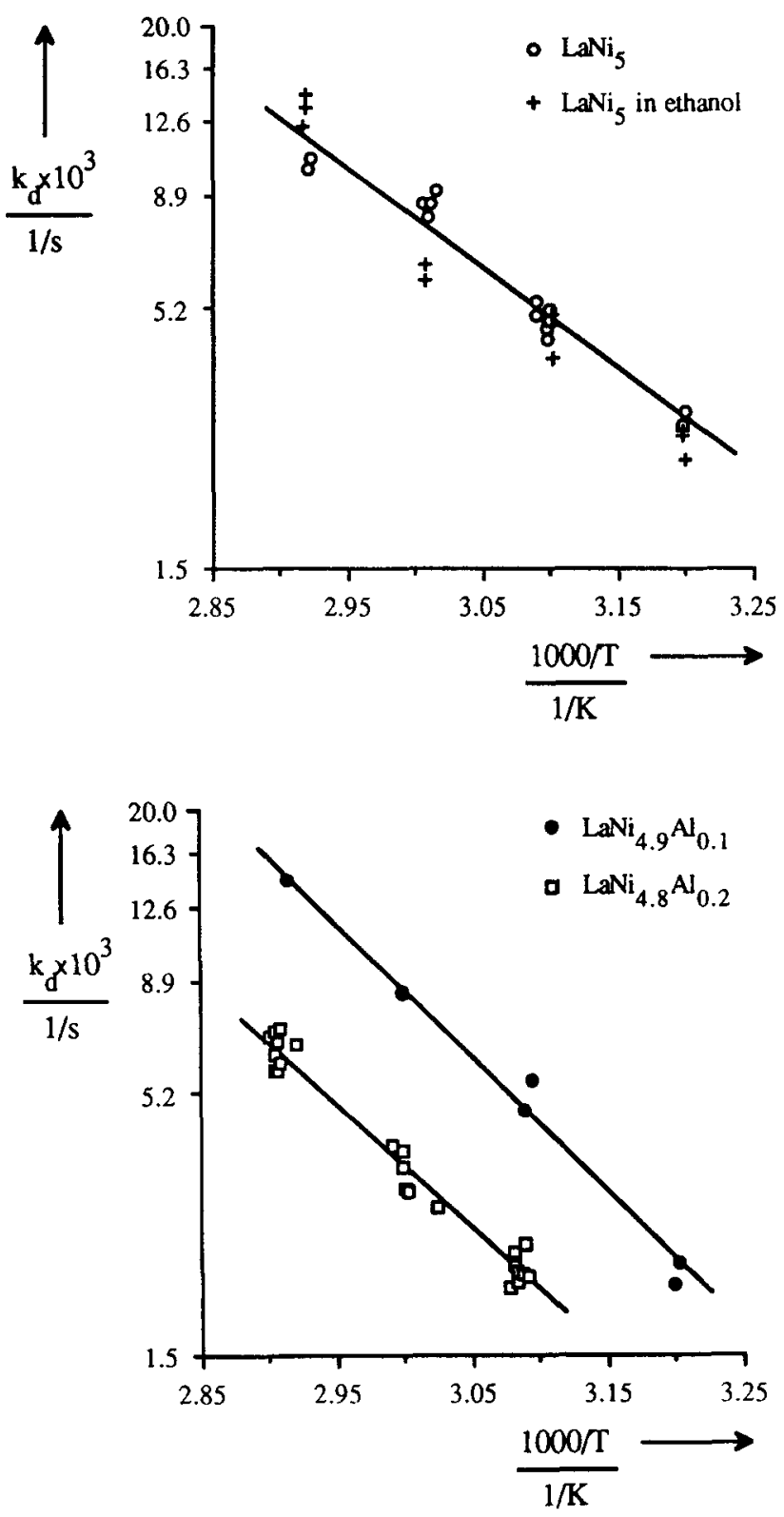

Figure 7a,b. Arrhenius plot for the desorption rate constants.

$$
\begin{array}{ll}
\mathrm{LaNi}_{4.9} \mathrm{Al}_{0.1} & k_{d}=2.0 \times 10^{6} \exp \left(\frac{-53.4 \times 10^{3}}{\mathrm{RT}}\right) \\
\mathrm{LaNi}_{4.8} \mathrm{Al}_{0.2} & k_{d}=184.2 \times 10^{3} \exp \left(\frac{-49.1 \times 10^{3}}{\mathrm{RT}}\right)
\end{array}
$$

\section{Discussion}

The hydrogen absorption rate appeared to change during an experiment, which has been demonstrated in Figure 3. Application of Eq. 6 gives the absorption rate as a function of $F / F_{\max }$, this is represented by the solid line in Figure 8 . The dotted line represents a hypothetical change of the reaction rate according to a three-dimensional nucleation and growth process (Rudman, 1983 and Tung et al., 1986): 


$$
\begin{gathered}
\frac{d F}{d t} \sim f(F) k_{b}(F)\left(P_{\mathrm{H}_{2}}-P_{\mathrm{eq}, a}\right) \\
f(F)=3(1-F)[-\ln (1-F)]^{2 / 3}
\end{gathered}
$$

The rate constant $k_{b}(F)$ is a summation of three resistances: surface process, bulk diffusion and the phase transformation. In the absence of a liquid, the absorption rate is generally not limited by a surface process. When the particles are suspended in a solvent however, a large part of the surface area is covered with liquid molecules and is inactive for hydrogen absorption.

ethanol:

cyclohexane:

$n$-undecane:

Pd5 silicon oil (Bayer):

The absorption rate is initially limited by a bulk process. As soon as the nuclei growth rate has become large enough, either of the two surface processes, chemisorption or dissociation of hydrogen, will be the rate determining step. Park and Lee (1982) presented relations for the hydrogen absorption rate in a hydride $\left(=d n_{H} / d t\right)$ in the case that one of those steps is rate limiting:

$$
\frac{d n_{H}}{d t}=K_{1} 4 \pi r_{0}^{2}\left(P_{\mathrm{H}_{2}}-P_{\mathrm{cq}, a}\right) \quad \text { (chemisorption of hydrogen) }
$$

$\frac{d n_{H}}{d t}=K_{2} 4 \pi r_{0}^{2} \frac{P_{\mathrm{H}_{2}}-P_{\mathrm{eq}, a}}{K_{b_{1}}+K_{f_{1}} P_{\mathrm{H}_{2}}} \quad$ (dissociation of hydrogen)

The constants $K_{1}, K_{2}, K_{b_{1}}$ and $K_{f_{1}}$ are defined by Park and Lee and include rate constants for the various steps of the equi-

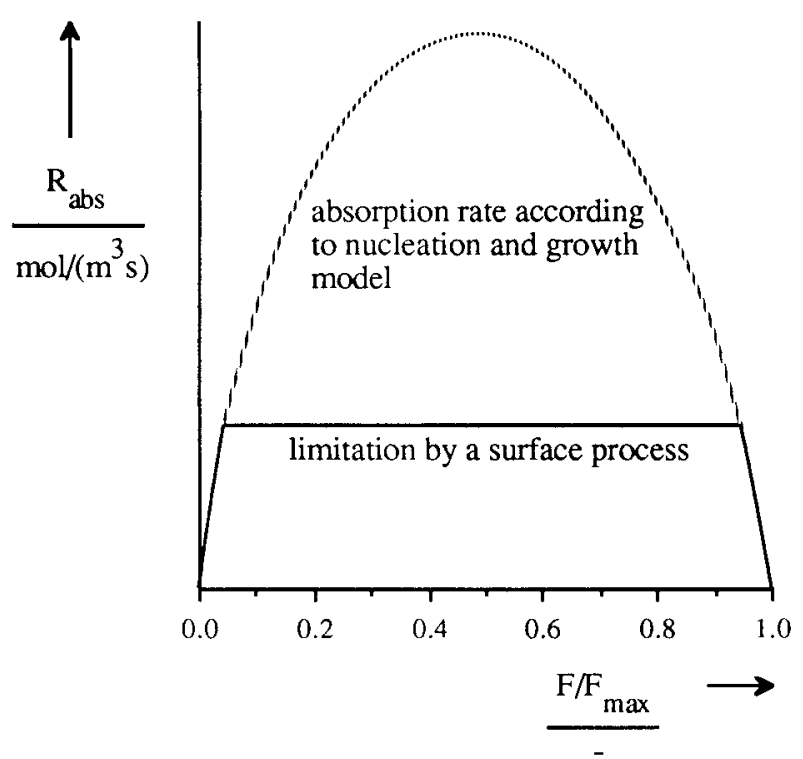

Figure 8. Variation of the absorption rate in a metal hydride slurry. librium reactions, $r_{0}$ denotes the particle radius. Both equations predict that the absorption rate is related to $P_{\mathrm{H}_{2}}-P_{\text {eq, } a}$ (Eq. 25: if $\left.K_{f_{1}} P_{\mathrm{H}_{2}} \ll K_{b_{1}}\right)$. Consequently, it is not possible to distinguish between these rate equations. However, since hydrogen dissociation is not a limiting process during the reaction with gaseous hydrogen, it is assumed that this step is not limiting either during absorption in a slurry. Consequently, the rate limiting step over a broad range of the absorption time is the chemisorption of hydrogen on the uncovered nickel surface.

This is in accordance with the influence of the solvent on the rate constants: some values for $\mathrm{LaNi}_{5}$ in several solvents at $298 \mathrm{~K}$ are $\left(\epsilon_{s}\right.$ is based on $\left.\rho_{\text {hydr }}=8,290 \mathrm{~kg} / \mathrm{m}^{3}\right)$ :

$\begin{array}{ll}k_{a} a_{s} / \epsilon_{s}=69.51 / \mathrm{s} & \text { (present work) } \\ k_{a} a_{s} / \epsilon_{s}=37.61 / \mathrm{s} \quad & \text { (present work) } \\ \left.k_{a} a_{s} / \epsilon_{s}=21.31 / \mathrm{s} \quad \text { (Tung et al., 1986, from data at } \epsilon_{s}=0.12\right) \\ k_{a} a_{s} / \epsilon_{s}=14.61 / \mathrm{s} \quad \text { (Holstvoogd et al., 1989) }\end{array}$

The rate constants will decrease when more nickel sites on the surface are covered with solvent molecules. The surface coverage is related to the binding strength between the nickel regions and the solvent molecules. Apparently, the larger molecules are bonded more strongly to the surface.

In the present work, the activation energy for absorption was found to be about $28 \mathrm{~kJ} / \mathrm{mol}$. This value is in good agreement with values reported by others. Holstvoogd et al. (1989) have found $32 \mathrm{~kJ} / \mathrm{mol}$ for a $\mathrm{LaNi}_{5} / \mathrm{Pd} 5$ silicon oil slurry and Tung et al. (1986) about $47 \mathrm{~kJ} / \mathrm{mol}$ for a $\mathrm{LaNi}_{5} /$ undecane slurry. In both cases surface adsorption was found to be the rate limiting step.

The rate constants $k_{a} a_{s} / \epsilon_{s}$ for absorption in cyclohexane slurries increase when the aluminum content in the metal alloy increases. This can be attributed partly to the corresponding increase in $a_{s}$, since it appears that the average particle diameters decrease at higher aluminum contents (Table 3 ). Holstvoogd (1988a) has reported a similar increase in the absorption activity for $\mathrm{LaNi}_{4,7} \mathrm{Al}_{0,3}$ and $\mathrm{LaNi}_{5}$, suspended in $\mathrm{Pd} 5$ silicon oil. Within the experimental accuracy, it can be concluded that the activation energies for hydrogen absorption in the three alloys are almost identical.

The hydrogen desorption process appeared to be limited by the phase transformation at the shrinking hydride core, as described by Eq. 21. Apparently, the hydrogen atoms are not hindered by the solvent molecules when they recombine on the surface and desorb into the gas phase. The liquid molecules on the surface are bypassed, as was already suggested by Reilly et al. (1989). During desorption no influence of the solvent is to be expected, which was confirmed by the experiments with $\mathrm{LaNi}_{5}$ in ethanol and cyclohexane. At higher aluminum contents the values of $k_{d}$ decrease. The results of Reilly et al. for $\mathrm{LaNi}_{5}$ in $n$-undecane produce a considerably lower value for $k_{d}$, for example, at $323 \mathrm{~K}$ :

present work: $k_{d}=5.0 \times 10^{-3} 1 / \mathrm{s}$

Reilly et al.: $k_{d}=1.5 \times 10^{-3} 1 / \mathrm{s}$

Also, the activation energy for $\mathrm{LaNi}_{4.9} \mathrm{Al}_{0.1}$ is higher than for both other alloys. The distinctions between the results may be attributed to small differences in the preparation technique of 
the various hydride suppliers and their respective effects on composition and homogeneity of the alloys. Moreover, the activation process can be slightly different.

For an industrial hydrogen recovery process, in which a metal hydride slurry is applied, it is desirable to achieve high absorption and desorption rates. Since desorption is not limited by mass-transfer steps in the liquid, increasing the amount of hydride will lead to a higher desorption rate. For absorption, the lowest value of the $k_{i} a$ and the $k_{a} a_{s}$ determines the overall absorption rate. Using data as presented in the present study, it can be concluded that particularly at higher temperatures or higher hydride fractions, the $k_{i} a$ becomes low as compared to the $k_{a} a_{s}$. According to Holstvoogd et al. (1986), enhancement of the mass-transfer rate can be expected, if metal hydride particles are present in the gas/liquid mass-transfer film. In that case, the particle diameter $d_{p}$ should be smaller than the film thickness $\delta$, or

$$
d_{p}<\frac{\mathrm{ID}_{\mathrm{H}_{2}}}{k_{l}}
$$

The relation for enhanced absorption reads (provided that the particles near the $\mathrm{G} / \mathrm{L}$ interface are not completely saturated, see Holstvoogd et al., 1986):

$$
R_{\mathrm{abs}}=k a E\left(P_{\mathrm{H}_{2}}-P_{\mathrm{eq}, a}\right)
$$

The enhancement factor $E$ is a function of the Hatta number, assuming a pseudo-homogeneous reaction in the slurry:

$$
E=\frac{H a}{\tanh (H a)} \text { with } H a=\sqrt{\frac{k_{a} a_{s} \mathrm{ID}_{\mathrm{H}_{2}}}{k_{l}^{2}}}
$$

The specific area $a_{s}$ depends on the average particle diameter and the hydride fraction in the slurry $\epsilon_{s}$ according to:

$$
a_{s}=\frac{6 \epsilon_{s} \phi}{d_{p}} \quad \text { with } \phi=\text { shape factor }=\frac{a_{s, \text { measured }}}{6 \epsilon_{s} / d_{p}}
$$

Equation 11 provides the measured $a_{s}$; finally, the kinetic rate constant $k_{a}$ can be obtained by dividing $k_{a} a_{s}$ by $a_{s}$. Combining Eqs. 28 and 29 yields:

$$
H a=\sqrt{\frac{6 k_{a} \epsilon_{s} \mathrm{ID} \mathrm{D}_{\mathrm{H}_{2}} \phi}{d_{p} k_{l}^{2}}}
$$

The experimental results of $\mathrm{LaNi}_{5}$ in cyclohexane which have been used to derive the required constants are:

\begin{tabular}{lll}
\hline \multicolumn{2}{c}{ Experimental data } & \multicolumn{1}{c}{ Derived } \\
\hline$\epsilon_{s}: \quad 0.0113$ & $\phi:$ & 4.7 \\
$d_{p}: \quad 11 \mu \mathrm{m}$ & $a_{s}:$ & $29 \times 10^{3} \mathrm{~m}^{2} / \mathrm{m}^{3}$ (with Eq. 11) \\
$k_{a} a_{s}: \quad 0.421 / \mathrm{s}$ & $k_{a}:$ & $1.48 \times 10^{-5} \mathrm{~m} / \mathrm{s}$ \\
$\mathrm{ID} \mathrm{D}_{2}: 9.2 \times 10^{-9} \mathrm{~m}^{2} / \mathrm{s}$ & \\
\hline
\end{tabular}

Figure 9 shows results at $298 \mathrm{~K}$ for the enhancement factor $E$ at various theoretical particle sizes and values for the $k_{1}$ and

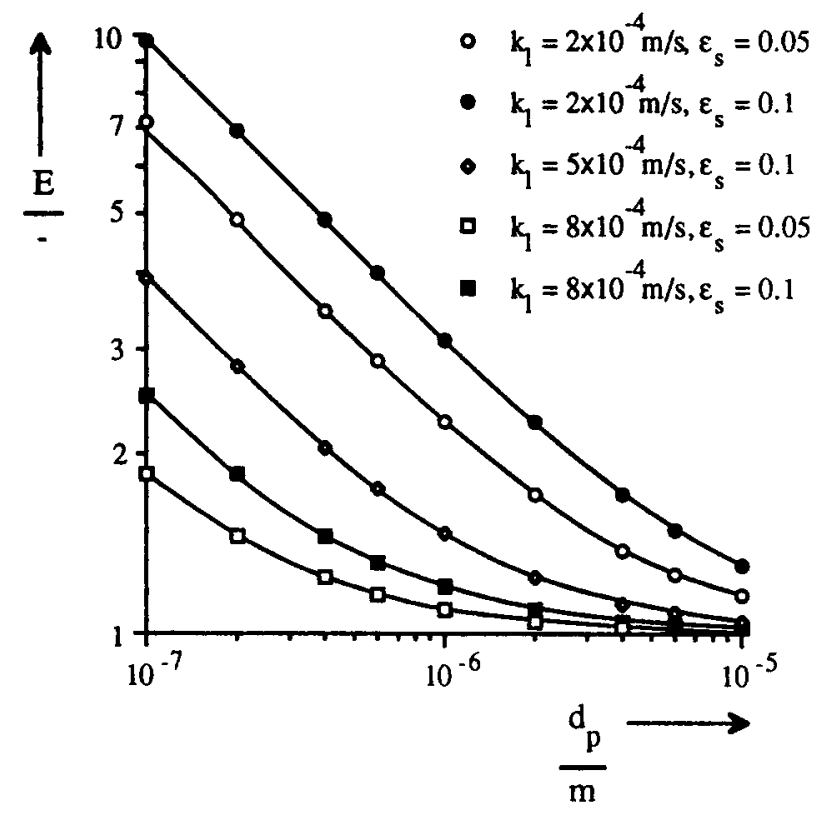

Figure 9. Enhancement factor for hydrogen absorption in a metal hydride slurry.

$\epsilon_{s}$. It appears that enhancement factors of about 10 can be achieved with very small particles and low mass-transfer coefficients $\left(d_{p}<<\delta\right.$ in these cases) combined with high hydride fractions. However, with industrially more realistic $k_{l}$ values $\left(5 \times 10^{-4}-1 \times 10^{-3} \mathrm{~m} / \mathrm{s}\right)$, the enhancement factor is rather small, even if it was possible to manufacture particles of 0.1 $\mu \mathrm{m}$. Moreover, the rate constants are lower in paraffin or silicon oils, which will be used in an industrial absorber (low vapor pressure), leading to a further reduction of the enhancement factor. This means that a reduction of the particle diameter, for example, by subsequent grinding, will have only a minor effect on the absorption rate in an industrial hydrogen absorption process.

For conditions as applied during the absorption experiments $\left(d_{p}=11 \times 10^{-6} \mathrm{~m}, \epsilon_{s}=0.011\right)$ the Hatta number is 0.08 . This indicates that the hydrogen absorption has not been enhanced provided that the metal hydride particles are very well wetted by the solvent (Holstvoogd et al., 1988b). Moreover, the particle diameters are not much smaller than the film thickness $\delta$. Consequently, for conditions as applied in the present work, it can be concluded that hydrogen absorption in the metal hydride slurries can be described with a mass-transfer and reaction resistances in series model. The absorption has not been enhanced.

\section{Conclusions}

Hydrogen absorption in several $\mathrm{LaNi}_{5-x} \mathrm{Al}_{x}$ slurries can be described with a mechanism which assumes mass transfer and reaction to be in series. For the reaction with the metal a firstorder rate equation was observed, $R=k_{d} a_{s}\left(C_{\mathrm{H}_{2}, s}-C_{\text {eq, } a}\right)$. This indicates that the absorption in a slurry is limited by a surface process, most likely the chemisorption of hydrogen on the metal surface. Lower absorption rates are observed in solvents with larger molecules. Apparently, the larger molecules exhibit a stronger interaction with the metal surface, resulting in a higher surface coverage. 
The increase in the rate constants at higher aluminum contents can partly be attributed to a corresponding increase in surface area.

Hydrogen desorption from a metal hydride slurry is limited by the phase transformation at the metal/metal hydride interface in the internal of the hydride particles. This process can be described with a shrinking core model: $1-(1-$ $X)^{1 / 3}=k_{d} \ln \left(P_{\text {eq }, d} / P_{\mathrm{H}_{2}}\right) t$. Since none of the processes on the surface of the particles is rate limiting, there was no influence observed of the solvent on the desorption rate. Increasing the aluminum content produces a lower reaction rate constant.

\section{Acknowledgments}

These investigations were supported by the Foundation for Chemical Research in the Netherlands (S.O.N.) and by DSM. We acknowledge H. J. Bakker, J. W. Dijkstra, Y. J. R. van Es, W. de Jong and T. D. Nauta for their contribution to the experimental work. We acknowledge also K. van Bree, S. Kuipers, A. H. Pleiter, A. Schanssema and $\mathrm{H}$. J. Vunderink for their technical support.

\section{Notation}

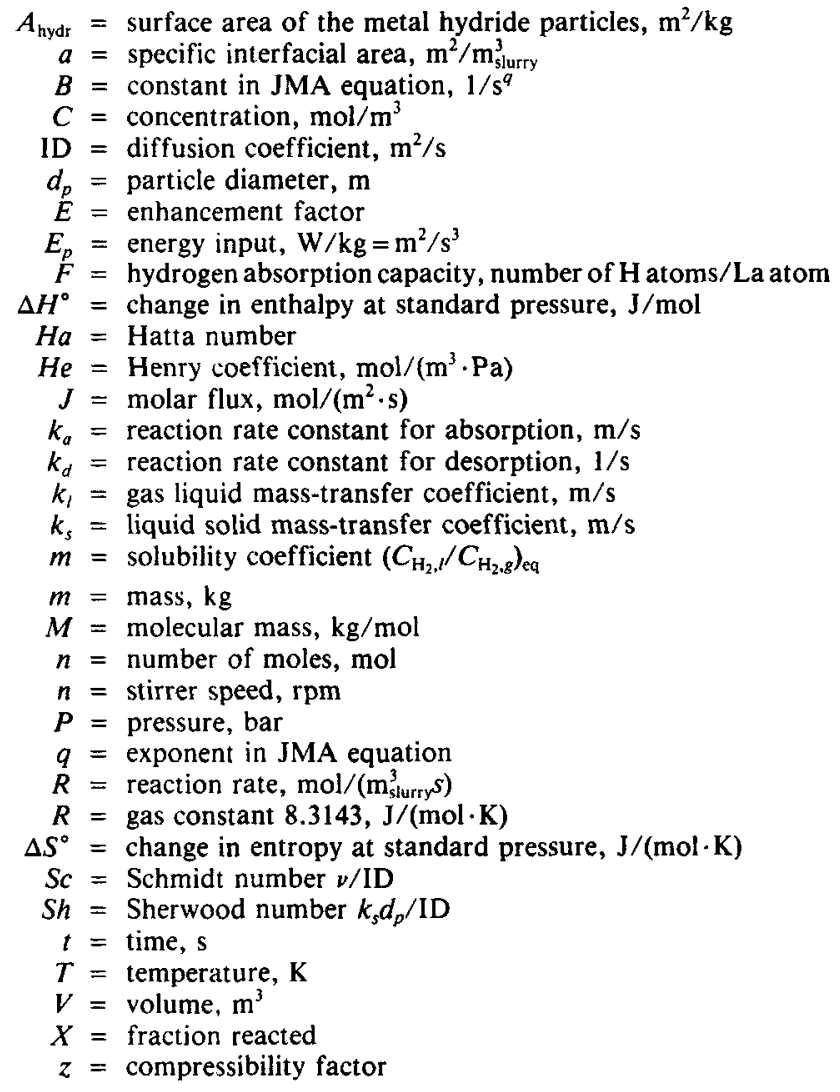

\section{Greek letters}

$\epsilon=$ volume fraction, defined as $V_{\text {hydr }} / V_{\text {slurry }}, \mathrm{m}_{\text {hydr }}^{3} / \mathrm{m}_{\text {slurry }}^{3}$

$\nu=$ kinematic viscosity, $\mathrm{m}^{2} / \mathrm{s}$

$\rho=$ density, $\mathrm{kg} / \mathrm{m}^{3}$

$\phi=$ shape factor

\section{Subscripts}

$a$, abs $=$ absorption

$d=$ desorption

eq $=$ equilibrium

$f=$ at final time

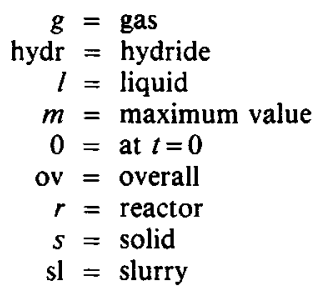

\section{Superscript}

$i=$ at the interface

\section{Literature Cited}

Armenante, P., "Mass Transfer to Microparticles in Agitated Systems," PhD thesis, Univ. of Virginia, Charlottesville (1983).

Avrami, M., "Kinetics of Phase Change, I General Theory," J. Chem. Phys., 7, pp. 1103-1112 (1939).

Avrami, M., "Kinetics of Phase Change, II Transformation-Time Relations for Random Distribution of Nuclei," J. Chem. Phys., 8, 212 (1940).

Avrami, M., "Granulation, Phase Change and Microstructure. Kinetics of Phase Change, III," J. Chem. Phys., 9, 177 (1941).

Bates, R. L., L. F. Philip, and R. R. Corpstein, "An Examination of Some Geometric Parameters of Impeller Power," Ind. Eng. Chem., Proc. Des. \& Dev., 2, 310 (1963).

Beenackers, A. A. C. M., and W. P. M. van Swaaij, "Development of a New Method for Production of Pressurized Pure Hydrogen from Low Pressure Nitrogen Containing Gas," in: Energy from Biomass Series E 3, G. Grassie and W. Palz, eds., pp. 201-205, Riedel, Dordrecht (1982).

Clever, H. L., "Solubility Data Series, Hydrogen and Deuterium," International Union of Pure and Applied Chemistry, p. 194, C. L. Young, ed., Pergamon Press, Oxford (1981).

Flanagan, T. B., "Kinetics of Hydrogen Absorption and Desorption," in: Hydrides for Energy Storage, A. F. Andressen and A. J. Maeland, eds., pp. 135-150. Pergamon Press, Oxford (1978).

Goodell, P. D., and P. S. Rudman, "Hydriding and Dehydriding Rates of the LaNi ${ }_{5}-\mathrm{H}$ System," J. Less Common Met., 89, 117 (1983).

Hancock, J. D., and J. H. Sharp, "Method of Comparing Solid-State Kinetic Data and its Application to the Decomposition of Kaolinite, Brucite and $\mathrm{BaCO}_{3}, " J$. Am. Cer. Soc., 55, 74 (1972).

Holstvoogd, R. D., K. J. Ptasinski, and W. P. M. van Swaaij, "Penetration Model for Gas Absorption with Reaction in a Slurry Containing Fine Insoluble Particles," Chem. Eng. Sci., 41, 867 (1986).

Holstvoogd, R. D., "The Absorption of Hydrogen in Metal Hydride Slurries, the Influence of Small Solid Particles on the Gas-Liquid Mass Transfer Rate," chapter 5 of PhD thesis, Univ. of Twente, Enschede, The Netherlands (1988a).

Holstvoogd, R. D., W. P. M. van Swaaij, and L. L. van Dierendonck, "The Absorption of Gases in Aqueous Activated Carbon Slurries Enhanced by Absorbing or Catalytic Particles,"' Chem. Eng. Sci., 43, 2182 (1988b).

Holstvoogd, R. D., W. P. M. van Swaaij, G. F. Versteeg, and E. D. Snijder, "Continuous Absorption of Hydrogen in Metal Hydride Slurries," Z. Phys. Chem. N.F., 164, 1429 (1989).

Johnson, W. A., and R. F. Mehl, "Reaction Kinetics in Processes of Nucleation and Growth," Trans. AIME, 135, 416 (1939).

Johnson, J. R., and J. J. Reilly, "Kinetics of Hydrogen Absorption by Metal Hydride Suspensions: the Systems $\mathrm{LaNi}_{5} \mathrm{H}_{x} / \mathrm{n}$-Octane and $\mathrm{LaNi}_{4.7} \mathrm{Al}_{0,3} \mathrm{H}_{x}$ /n-Undecane," $Z$. Phys. Chem. N.F., 147, 263 (1986).

Littel, R. J., G. F. Versteeg, and W. P. M. van Swaaij, "Diffusivity Measurements in some Organic Liquids by a Gas-Liquid Diaphragm Cell," J. Chem. Eng. Data, 37, 42 (1992).

Marrone, G. M., and D. J. Kirwan, "Mass Transfer to Suspended Particles in Gas-Liquid Agitated Systems," AIChE J., 32, 523 (1986).

Park, C. N., and J. Y. Lee, "A Study on the Kinetics of Hydriding of the $\mathrm{LaNi}_{5}$ System," J. Less Common Met., 83, 39 (1982).

Ptasinski, K. J., A. A. C. M. Beenackers, W. P. M. van Swaaij, and R. D. Holstvoogd, "Hydrogen Recovery from Gas Mixtures using Metal Hydrides Suspended in Slurry," in: Energy from Biomass, 
Series E 8, A. A. C. M. Beenackers and W. P. M. van Swaaij, eds., Riedel, Dordrecht, pp. 229-238 (1986).

Reilly, J. J., and R. H. Wiswall, "The Reaction of Hydrogen with Alloys of Magnesium and Nickel and the Formation of $\mathrm{Mg}_{2} \mathrm{NiH}_{4}$," Inorg. Chem., 7, 2254 (1968).

Reilly, J. J., and R. H. Wiswall, "Formation and Properties of Iron Titanium Hydride," Inorg. Chem., 13, 218 (1974).

Reilly, J. J., "Metal Hydrides as Hydrogen Storage Media and Their Applications," in: Hydrogen, its Technology and Implications, 2 , K. E. Cox and K. D. Williamson, eds., CRC Press, Cleveland, pp. 13-48 (1977).

Reilly, J. J., Y. Joseph, and J. R. Johnson, “Kinetics of the Isothermal Decomposition of Lanthanum Nickel Hydride," Z. Phys. Chem. N.F., 164, 1241 (1989).

Rudman, P.S., "Hydriding and Dehydriding Kinetics," J. Less Common Met., 89, 93 (1983).

Sano, Y., N. Yamaguchi, and T. Adachi, "Mass Transfer Coefficients for Suspended Particles in Agitated Vessels and Bubble Columns," J. Chem. Eng. Jpn., 7, 255 (1974).

Snijder, E. D., "Metal Hydrides as Catalysts and Hydrogen Carriers," PhD thesis, Univ. of Twente, Enschede, The Netherlands (1992).
Snijder, E. D., G. F. Versteeg, and W. P. M. van Swaaij, "Hydrogenation of Cyclohexene with $\mathrm{LaNi}_{5-x} \mathrm{Al}_{x} \mathrm{H}_{n}$ Metal Hydrides, Suspended Cyclohexane or Ethanol," Accepted for publication in Chem. Eng. Data (1992).

Tung, Y., E. W. Grohse, and F. B. Hill, "Kinetics of Hydrogen Absorption in a Stirred Metal Hydride Slurry," AIChE J., 32, 1821 (1986).

Vucht, J. H. N., F. A. van Kuijpers, and H. C. A. M. Bruning, "Reversible Room Temperature Absorption of Large Quantities of Hydrogen by Intermetallic Compounds," Philips Res. Rep., 25, 133 (1970).

Wallace, W. E., R. F. Karlicek, and H. Imamura, "Mechanism of Hydrogen Absorption by LaNi $i_{5}$," J. Phys. Chem., 83, 1708 (1979).

Wallace, W. E., A. Elattar, H. Imamura, R. S. Craig, and A. G. Moldovan, "Intermetallic Compounds: Surface Chemistry, Hydrogen Absorption and Heterogeneous Catalysis," in: Sci. Technol. Rare Earth Mater., E. C. Subbarao and W. E. Wallace, eds., pp. 329-351, Academic Press, New York (1980).

Manuscript received Aug. 12, 1992, and revision received Dec. 28, 1992. 